\title{
Evaluation of the Barricor Tube in 28 Routine Chemical Tests and Its Impact on Turnaround Time in an Outpatient Clinic
}

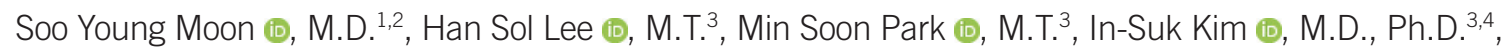 \\ and Sun Min Lee (1), M.D. ${ }^{3}$ \\ ${ }^{1}$ Department of Laboratory Medicine, ${ }^{2}$ Biomedical Research Institute, Pusan National University Hospital, Busan, Korea; ${ }^{3}$ Department of Laboratory \\ Medicine, Pusan National University Yangsan Hospital, Yangsan, Korea; ${ }^{4}$ Department of Laboratory Medicine, Pusan National University School of Medicine, \\ Yangsan, Korea
}

Background: We recently introduced the Barricor (BD, Franklin Lakes, NJ, USA) plasma separation tube, which uses a mechanical separator instead of a gel. We evaluated the effects of using the Barricor tube in a stat (statin) laboratory on the results and turnaround time (TAT) of routine chemical tests. We verified the impact of Barricor tube on reducing TAT and providing results similar to those obtained using serum separator tubes (SSTs).

Methods: We collected venous blood samples from 166 outpatients in Barricor tubes and SSTs and measured 28 routine analytes using an AU5800 instrument (Beckman Coulter, Brea, CA, USA). TAT indexes were compared before and after using Barricor tube.

Results: Mean percent differences were $<5 \%$, except for alanine aminotransferase, total $\mathrm{CO}_{2}$, high-density lipoprotein, phosphate, total protein, and direct bilirubin. The median TAT decreased from 45 to 38 minutes, and the rate of a TAT > 60 minutes decreased from $7.84 \%$ to $2.66 \%$, which was approximately one-third of that for SST. The reduction in TAT was attributable to a decrease in centrifugation time. Incomplete clotting and repeated centrifugation, which occurred frequently when using SST, also decreased after using the Barricor tubes.

Conclusions: The Barricor tube is an alternative to SST for routine chemical tests in institutions aiming to reduce TAT, with clinically allowable differences in test results.

Key Words: Barricor tube, Turnaround time, Routine chemical tests, Serum separation tube
Received: April 21, 2020

Revision received: June 17, 2020

Accepted: November 30, 2020

Corresponding author: Sun Min Lee, M.D. Department of Laboratory Medicine, Pusan National University Yangsan Hospital, 20 Geumo-ro, Mulgeum-eup, Yangsan 50612, Korea

Tel: +82-55-360-1878

Fax: $+82-55-360-1880$

E-mail: yaong97@pnuyh.co.kr

\section{(i) (8)}

(c) Korean Society for Laboratory Medicine

This is an Open Access article distributed under the terms of the Creative Commons Attribution Non-Commercial License (https://creativecommons.org/licenses/by-nc/4.0) which permits unrestricted non-commercial use, distribution, and reproduction in any medium, provided the original work is properly cited.

\section{INTRODUCTION}

Reducing the turnaround time (TAT) is important in clinical laboratories, especially for emergency and outpatient departments, as it can facilitate faster clinical decision making [1]. Improvements in automation of laboratory instruments and transport technology have reduced TAT, especially for the analysis and post-analysis components. For routine chemistry tests, most laboratories receive serum samples that require clotting. Despite the use of a clot-activation gel, serum separator tubes (SSTs) re- quire approximately 10 minutes each for clotting and centrifugation. To reduce the length of this preanalytical step, the plasma separation tube (PST) and Barricor tube (BD, Franklin Lakes, NJ, USA) were developed. A PST usually contains lithium heparin as an anticoagulant, and numerous PSTs are available from different manufacturers [2]. However, a few studies have shown that the degree of hemolysis is higher in the PST than in the SST $[3,4]$.

Recently Becton, Dickinson and Company (BD; Franklin Lakes, NJ, USA) introduced the Barricor tube, a PST with a mechani- 
cal separation device (stopper). The stopper consists of two parts: an elastomer top that stretches during centrifugation, sealing the stopper to the tube walls, and a high-density plastic base that forms a barrier between the cells and plasma through differential buoyancy. The Barricor tube uses lithium heparin as an anticoagulant; therefore, no clotting step is required. In addition, centrifugation time is shorter for the Barricor tube (3-5 minutes) than for the SST (10 minutes). Therefore, using the Barricor tube could considerably reduce TAT.

The efficacy of the Barricor tube and its ability to reduce TAT compared with the SST have been reported recently $[5,6]$. We compared the results of routine chemical tests performed using the SST and the Barricor tube and evaluated the change in TAT and the hemolysis index after switching to the Barricor tube in a one-day visiting department, the third-floor unit. Before Barricor tube introduction, an average of 10,200 SSTs were collected per month: 4,500 in the third-floor phlebotomy unit and 5,700 in the first-floor phlebotomy unit. Of these, 4,300 (95\%) from the third-floor unit and 2,000 (35\%) from the first-floor unit were requested for stat tests, the results of which are required early. Further, the one-day visiting department receives samples from patients and provides results to doctors before the patients meet the doctors, i.e., in one day. Therefore, we aimed to reduce the TAT of stat tests in the third-floor phlebotomy unit.

\section{MATERIALS AND METHODS}

\section{Clinical setting and switch to the Barricor tube (September 1, 2017)}

Pusan National University Yangsan Hospital at Yangsan, is a national university hospital serving the northern residential region of Busan City, Korea. The hospital has 1,200 beds for inpatients and serves 50,000 outpatients per month. The clinical laboratory is located on the third floor of the main hospital building, and a phlebotomy unit for stat (statin) tests is located adjacent to the laboratory. This phlebotomy unit mainly serves one-day outpatients (7,000 patients per month) whose blood samples are collected, analyzed, and reported before they meet the doctors.

The preanalytical process in the third-floor phlebotomy unit is as follows. After the patient registers at the phlebotomy unit, a label containing information and barcode is printed and affixed to a blood tube using a GNT7 automated tube labeling system (Energium, Siheung, Korea). After blood collection, the phlebotomist presses a keyboard button labeled "Blood collection finished" to call the next patient and manually classifies stat test tubes in a basket. Stat test tubes are recommended to be trans- ferred to the central laboratory every 10 minutes. In the laboratory, a technician receives and registers stat test tubes using a barcode reader. Registered SSTs are centrifuged for 10 minutes in a Kubota 4000 instrument (Kubota, Tokyo, Japan) at 2,270x $g$, and Barricor tubes are centrifuged for 5 minutes in an Eppendorf 5804 instrument (Eppendorf, Hamburg, Germany) at $3,234 \times g$. This difference in centrifugation conditions was the only change in the preanalytical process after introduction of the Barricor tube on September 1, 2017. According to recommendations by experts and SST suppliers, standing for 30 minutes was required to complete coagulation [7]. Since our laboratory is located right next to the third-floor phlebotomy unit, serum samples were frequently analyzed without complete clotting. This incomplete clotting often led to repeated centrifugation, fibrin removal, and clogging of the analyzer aspirators. To overcome these problems, we replaced the SST with the Barricor tube in the third-floor phlebotomy unit from September 1, 2017. Among the orders from the outpatient clinic, only stat test samples, for which physicians clicked "EM" (i.e., emergency), were collected in Barricor tubes. The only change to laboratory equipment or manpower was the addition of a small table for a new centrifuge.

\section{Routine chemical tests}

The study included 166 patients (adults older than 18 years) who visited the stat test phlebotomy unit on the third floor between March 17 and March 24, 2017. All included patients provided written informed consent. The Institutional Review Board of Pusan National University Yangsan Hospital approved this study (No. 05-2016-041). Blood was sampled as per the CLSI guidelines GP41 7th edition, using a 21-G needle and Vacutainer holder (BD Life Science, Seoul, Korea) [8]. From each patient, at least $3 \mathrm{~mL}$ of venous blood was collected in a VACUETTE Tube $5 \mathrm{~mL}$ serum separator (Greiner Bio-One, Kremsmünster, Austria) and another $3 \mathrm{~mL}$ in a Barricor tube. After collection, both tubes were centrifuged and transferred to the routine chemistry unit [9]. The $5 \mathrm{~mL} \mathrm{SST}$ is a $13 \times 100 \mathrm{~mm}$ polyethylene terephthalate (PET) tube containing an olefin oligomer barrier gel as a separator and dried microscopic silica particles as clot activators, and the $5.5 \mathrm{~mL}$ Barricor tube is a $13 \times 100 \mathrm{~mm}$ PET tube containing $93.5 \mathrm{IU}$ of dried lithium heparin and a mechanical separator.

The 28 analytes were albumin, alanine alkaline phosphatase, alanine aminotransferase (ALT), amylase, aspartate aminotransferase (AST), blood urea nitrogen, calcium (Ca), chloride (Cl), cholesterol (Chol), creatine kinase (CK), carbon dioxide $\left(\mathrm{CO}_{2}\right)$, creatinine, C-reactive protein, direct bilirubin (Dbil), $\gamma$-glutamyl- 
transferase, glucose, high-density lipoprotein (HDL), potassium $(K)$, lactate dehydrogenase (LDH), low-density lipoprotein, lipase, magnesium $(\mathrm{Mg})$, phosphate $(\mathrm{P})$, sodium $(\mathrm{Na})$, total bilirubin (Tbil), triglyceride, total protein (Tpro), and uric acid (UA). The analytes were measured using an AU5800 instrument (Beckman Coulter, Brea, CA, USA) with the same lot of dedicated reagents.

\section{TAT}

TAT was compared between four months each before and after the introduction of the Barricor tube (May to August 2017 vs. September to December 2017). In the third-floor phlebotomy unit, the time point at which the "Blood collection finished" button was pressed was considered the collection time. By contrast, in the first-floor phlebotomy unit, the time point at which the barcode was printed was considered the collection time. The time point at which the technician registered the sample before centrifugation was considered the acceptance time. The time point at which the AU5800 reported the results to the interface software was considered the result time. More than $90 \%$ of the results were automatically verified and reported to the laboratory information system (LIS) portal, and this time point was recorded as the report time. We used the AST test to monitor TAT because it is one of the most frequently requested tests. A small proportion of SST samples (9.4\%) were for tests other than AST, but AST was considered representative of the 28 analytes.

TAT was defined as the interval between the collection time and the report time. Generally, physicians consider TAT to be the interval from order to report; however, for a one-day patient, a sample is typically ordered during the previous visit (potentially weeks or months before the current visit). Therefore, we decided to calculate the entire TAT from blood collection to reporting. Each month, the TAT of AST tests in the first- and third-floor phlebotomy units was analyzed. The median and 90th percentile TAT for stat tests and the proportion of samples that exceeded the TAT limit (60 minutes) were estimated four months before and after the introduction of the Barricor tube. The TAT of the firstfloor phlebotomy unit was presented as a reference, because no switch to the Barricor tube was made in this unit. We aimed to show that no change other than the introduction of the Barricor tube was made in the analytical and post-analytical phases in our laboratory.

For quality control, our laboratory requires that technicians document the reason for a sample exceeding the TAT limit in the LIS. Beginning in June 2017, 14 reasons were documented (e.g., incomplete clotting and centrifugation, instrument inspec- tion, reagent problem, error flag, delayed result verification, and sample dilution). The number of blood tubes that exceeded the TAT limit and their reasons were retrospectively investigated on the basis of sample and not analyte during the same period.

\section{Hemolysis index}

We measured the hemolysis index semi-quantitatively using the Beckman Coulter LIH reagent in the AU5800 instrument. According to the manufacturer's instructions, the measured hemolysis index was classified as $\mathrm{N},+,++$, and +++ , which represent approximately $<0.5,0.5-0.99,1-1.99$, and $2-2.99 \mathrm{~g} / \mathrm{L}$ of hemoglobin (a higher degree of hemolysis was not observed in the study period). To estimate hemolytic samples, the ratio of a positive hemolysis index $(+,++$, and +++$)$ to the total requested samples was compared before and after introduction of the Barricor tube. Outpatient results with a positive hemolysis index were usually reported with a warning comment. To ensure comparability, only tubes requested for stat tests in the third-floor phlebotomy unit in the two months before and after introduction of the Barricor tube were analyzed.

\section{Statistical analysis}

Bland-Altman difference was analyzed to estimate relative differences between test results of SST and Barricor and 95\% limits of agreement for the difference. Because none of the anaIytes exhibited Gaussian distributions, the Wilcoxon signed-rank test was used to compare medians. The mean difference between the SST and the Barricor tube was compared to allowable bias, which was calculated from the recently updated biological variation provided by the European Federations of Laboratory Medicine (EFLM) [10]. The allowable bias equals the desirable bias, given on the website as desirable bias $=0.25 \sqrt{ }\left(C V_{i}^{2}+C V_{g}^{2}\right)$, where $C V_{i}$ and $C V_{g}$ are the medians of the within- and betweensubject CV estimates, respectively. For some analytes (Ca, Dbil, $\mathrm{Mg}$, $\mathrm{P}, \mathrm{Tbil}$, and $\cup \mathrm{A}$ ) biological variation data are not available in the EFLM database; these were evaluated with reference to the Ricos database [11]. Independent $t$-tests and chi-square tests were performed as appropriate. The Analyse-it ver. 5.10.9 (Analyse-it Software, Leeds, UK) added to Excel 2013 (Microsoft, Redmond, WA, USA) was used for statistical analyses.

\section{RESULTS}

\section{Biochemical tests}

For the 166 paired clinical samples, most analytes showed acceptable bias between the SST and the Barricor tube (Table 1). 
Table 1. Routine chemical test results using the SST and the Barricor tube $(\mathrm{N}=166)$

\begin{tabular}{|c|c|c|c|c|c|c|c|}
\hline Analyte & Unit & Measured range & $\begin{array}{c}\text { Mean \% } \\
\text { difference }\end{array}$ & $\begin{array}{l}95 \% \text { limit of } \\
\text { agreement }\end{array}$ & $\begin{array}{c}\text { Allowable } \% \\
\text { bias }\end{array}$ & $P$ & Comments on unallowable bias \\
\hline Alb & $g / L$ & $24.1-53.5$ & -0.19 & $-4.26-3.88$ & 1.43 & 0.5316 & \\
\hline ALP & $\mu k a t / L$ & $0.69-7.75$ & -3.37 & $-7.98-1.24$ & 6.10 & $<0.0001$ & \\
\hline ALT & $\mu k a t / L$ & $0.14-5.37$ & -8.57 & $-27.93-10.78$ & 7.75 & $<0.0001$ & Low ALT level \\
\hline Amy & $\mu k a t / L$ & $0.16-3.04$ & -0.24 & $-5.45-4.96$ & 7.73 & 0.3384 & \\
\hline AST & $\mu k a t / L$ & $0.16-5.86$ & -2.34 & $-16.92-12.24$ & 5.63 & $<0.0001$ & \\
\hline BUN & $\mathrm{mmol} / \mathrm{L}$ & $3.25-45.7$ & -0.51 & $-3.93-2.9$ & 6.15 & 0.0003 & \\
\hline $\mathrm{Ca}$ & $\mathrm{mmol} / \mathrm{L}$ & $1.89-2.48$ & -1.35 & $-5.24-2.54$ & $0.82^{*}$ & $<0.0001$ & Strict allowable bias criteria \\
\hline Chol & $\mathrm{mmol} / \mathrm{L}$ & $2.06-9.96$ & -2.17 & $-5.8-1.46$ & 4.52 & $<0.0001$ & \\
\hline CK & $\mu k a t / L$ & $0.21-9.81$ & -0.82 & $-14.14-12.5$ & 8.90 & 0.0005 & \\
\hline $\mathrm{Cl}$ & $\mathrm{mmol} / \mathrm{L}$ & $95.6-112.2$ & 0 & $-2.17-2.16$ & 0.43 & 0.0547 & \\
\hline $\mathrm{CO}_{2}$ & $\mathrm{mmol} / \mathrm{L}$ & $14.8-29$ & 18.12 & $-1.93-38.18$ & $1.68^{*}$ & $<0.0001$ & Impaired stability, strict bias criteria \\
\hline Cre & $\mu \mathrm{mol} / \mathrm{L}$ & $38.9-746.1$ & -2.26 & $-8.14-3.61$ & 3.75 & $<0.0001$ & \\
\hline CRP & $\mathrm{mg} / \mathrm{L}$ & $0.07-189$ & -1.85 & $-14.29-10.6$ & 23.65 & $<0.0001$ & \\
\hline Dbil & $\mu \mathrm{mol} / \mathrm{L}$ & $0.51-226.29$ & 13.4 & $-78.49-105.3$ & $14.19^{*}$ & 0.053 & \\
\hline GGT & $\mu k a t / L$ & $0.14-29.02$ & -1.74 & $-11.86-8.38$ & 10.56 & $<0.0001$ & \\
\hline Glu & $\mathrm{mmol} / \mathrm{L}$ & $4.30-17.65$ & -1.35 & $-5.71-3.01$ & 2.38 & $<0.0001$ & \\
\hline $\mathrm{HDL}$ & $\mathrm{mmol} / \mathrm{L}$ & $0.57-3.07$ & -5.06 & $-15.19-5.08$ & 6.34 & $<0.0001$ & Allowable but significant \\
\hline K & $\mathrm{mmol} / \mathrm{L}$ & $3.45-6.42$ & -2.69 & $-9.91-4.53$ & 1.47 & $<0.0001$ & Unallowable bias \\
\hline LDH & $\mu k a t / L$ & $4.11-38.6$ & -0.87 & $-15.09-13.36$ & 3.38 & 0.0167 & \\
\hline LDL & $\mathrm{mmol} / \mathrm{L}$ & $0.61-251.3$ & -1.7 & $-6.84-3.45$ & 6.85 & $<0.0001$ & \\
\hline Lip & $\mu k a t / L$ & $0.07-2.43$ & -1.29 & $-7.96-5.38$ & 6.61 & $<0.0001$ & \\
\hline $\mathrm{Mg}$ & $\mathrm{mmol} / \mathrm{L}$ & $0.51-1.10$ & -1.72 & $-7.22-3.78$ & $1.84^{*}$ & $<0.0001$ & \\
\hline $\mathrm{Na}$ & $\mathrm{mmol} / \mathrm{L}$ & $126.7-147.8$ & 0.13 & $-2.19-2.45$ & 0.30 & 0.0001 & \\
\hline$P$ & $\mathrm{mmol} / \mathrm{L}$ & $0.77-1.78$ & -4.02 & $-9.71-1.67$ & $3.38^{*}$ & $<0.0001$ & Unallowable bias \\
\hline Tbil & $\mu \mathrm{mol} / \mathrm{L}$ & $4.45-470.19$ & 1.24 & $-5.92-8.4$ & $8.95^{*}$ & 0.0004 & \\
\hline $\mathrm{TG}$ & $\mathrm{mmol} / \mathrm{L}$ & $0.41-8.59$ & -2.14 & $-5.44-1.15$ & 10.23 & $<0.0001$ & \\
\hline Tpro & $g / L$ & $55.3-88.2$ & 4.24 & $-0.64-9.12$ & 1.32 & $<0.0001$ & Unallowable bias \\
\hline UA & $\mathrm{mmol} / \mathrm{L}$ & $0.12-0.56$ & -0.2 & $-3.26-2.87$ & $4.87^{*}$ & 0.7904 & \\
\hline
\end{tabular}

Mean percent differences (Barricor tube minus SST) and 95\% limits of agreement were calculated from Bland-Altman plots. $P$ was determined using the Wilcoxon signed-rank test. The criteria for allowable \%bias were calculated using the EFLM biological variation database [10], except for * analytes (calculated using the Westgard biological variation database).

Abbreviations: SST, serum separator tubes; Cl, confidence interval; Alb, albumin; ALP, alanine alkaline phosphatase; ALT, aminotransferase; Amy, amylase; AST, aspartate aminotransferase; BUN, blood urea nitrogen; $\mathrm{Ca}$, calcium, $\mathrm{Cl}$, chloride; Chol, cholesterol; $\mathrm{CK}$, creatine kinase; $\mathrm{CO}_{2}$, carbon dioxide; Cre, creatinine; CRP, c-reactive protein; Dbil, direct bilirubin; GGT, $\gamma$-glutamyltransferase; Glu, glucose; HDL, high-density lipoprotein cholesterol; K, potassium; LDH, lactate dehydrogenase; LDL, low-density lipoprotein cholesterol; Lip, lipase; Mg, magnesium; Na, Sodium; P, phosphate; Tbil, total bilirubin; TG, triglyceride; Tpro, total protein; UA, uric acid; EFLM, European Federations of Laboratory Medicine.

The mean percent difference based on the Bland-Altman plot was $<5 \%$ for 22 analytes and $>5 \%$ for six (ALT, $\mathrm{CO}_{2}$, Dbil, $\mathrm{HDL}$, $\mathrm{P}$, and Tpro). Other electrolytes and proteins were present in a narrow range; therefore, a bias plot was generated to interpret the differences. Compared with those in the SST, Tpro level increased and $\mathrm{HDL}, \mathrm{K}$, and $\mathrm{P}$ levels decreased in the Barricor tube to within the tolerable range (Fig. 1).
We found significant differences between the SST and the Barricor tube for 17 out of the 22 analytes $(P<0.05$, Wilcoxon signedrank test), although most of these differences were within the desirable percent bias suggested by the EFLM [10]. Because the desirable percent bias was calculated based on a meta-analysis of biological variation databases, some criteria were excessively stringent for use in routine laboratory practice. For exam- 

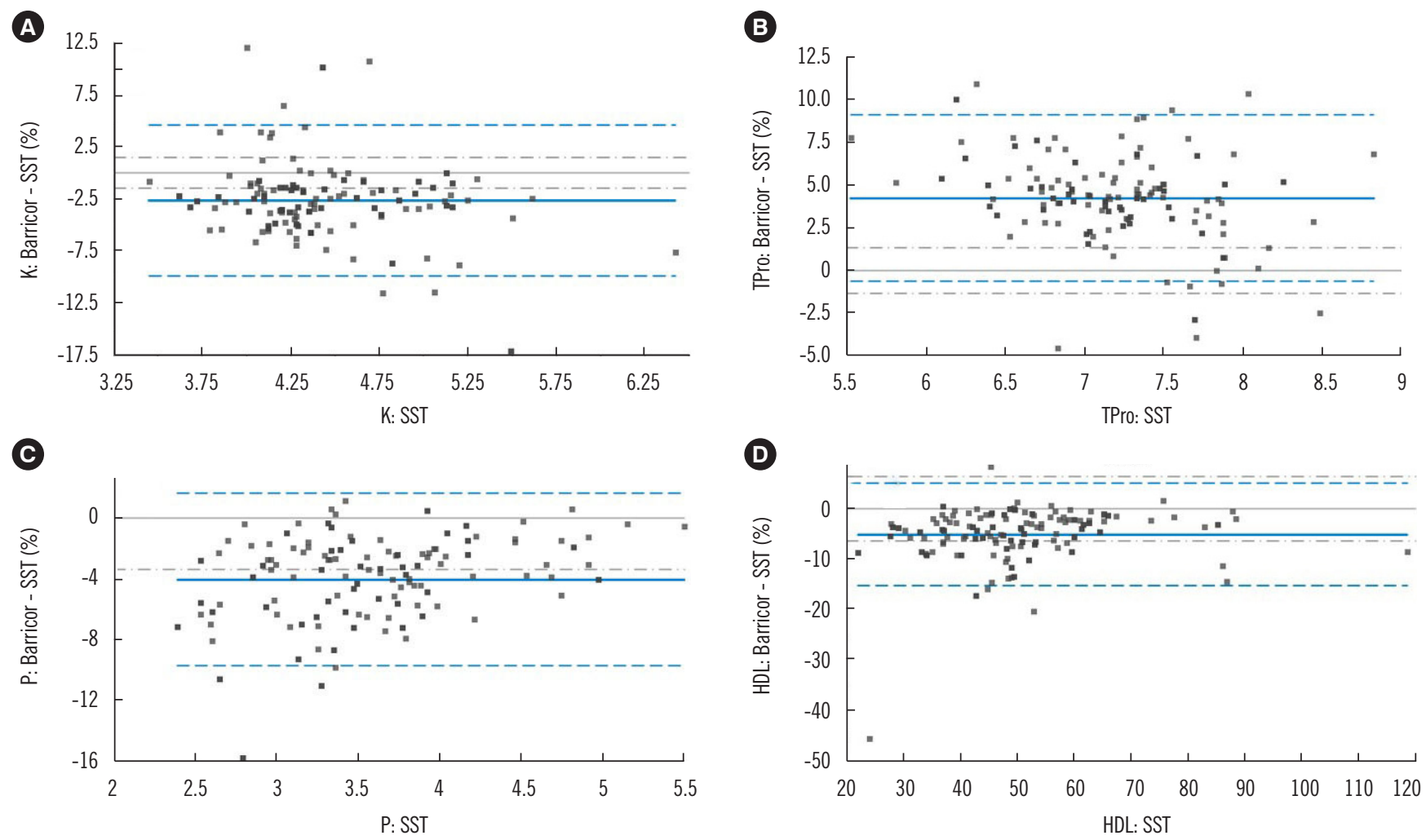

Fig. 1. Some analytes showed bias between the SST and the Barricor tube. Bland-Altman percent bias plots for K, Tpro, P, and HDL for the two tubes in 166 patients. Blue solid line, mean percent bias; blue broken lines, 95\% LoA; gray broken lines, allowable percent bias. Detailed values of mean bias, 95\% LoA, and allowable percent bias are described in Table 1.

Abbreviations: HDL, high-density lipoprotein cholesterol; K, potassium; LoA, limit of agreement; P, phosphorus; SST, serum separator tube; Tpro, total protein.

ple, Ca showed a $-1.35 \%$ mean difference between the Barricor tube and the SST, exceeding the desirable bias of $0.82 \%$. Conversely, HDL showed $-5.06 \%$ mean bias, which was within the desirable $6.34 \%$ bias; this difference was notable and has been presented in a bias plot. The subtle absolute differences in the low ALT and Dbil levels were exaggerated in the \% bias difference (i.e., ALT 0.3 vs. $0.22 \mu \mathrm{kat} / \mathrm{L}$, Dbil 1.3 vs. $2.17 \mu \mathrm{mol} / \mathrm{L}$ ); however, this was not considered clinically significant.

In summary, most analytes showed clinically acceptable differences after using the Barricor tube, with a few notable changes.

\section{TAT}

The number of requested tests, median and 90th percentile TAT, and number and proportion of tests that exceeded the TAT limit (60 minutes) were monitored monthly for eight months in the two phlebotomy units (Table 2). The proportion of tests that exceeded the TAT limit in total tests was regarded the "over rate." After introducing the Barricor tube in the third-floor phlebotomy unit, the median TAT significantly decreased by 7 minutes, and the $90 \%$ TAT decreased by 8 minutes. The major contributor to the reduction in TAT was the reduction in centrifugation time, from 10 minutes to 5 minutes. The over rate decreased from $7.84 \%$ to $2.66 \%$, indicating that the number of samples delayed excessively was reduced by one-third. This effect was most noticeable in the first month after introducing the Barricor tube. The number of tests that exceeded the TAT limit decreased by $25 \%$ in the first month of Barricor tube use (September), but increased slightly in the next month (October).

The TAT of stat tests requested in the first-floor phlebotomy unit was not significantly different in the same period $(P=0.48$ ). Because the first-floor phlebotomy unit serves mainly outpatients who do not need their results before they meet doctors, the proportion and number of stat tests were lower. The TAT was higher because of the distance between the first-floor phlebotomy unit and the laboratory, but the difference was not statistically significant, indicating that the analytic process was not affected by the introduction of the Barricor tube.

The over rate due to insufficient clotting and repeated centrifugation decreased after introduction of the Barricor tube. Incomplete clotting and repeated centrifugation contributed to one-fifth 
Table 2. TAT after introduction of the Barricor tube (September 2017) in the phlebotomy unit for outpatient stat tests

\begin{tabular}{|c|c|c|c|c|c|c|c|c|c|c|c|c|}
\hline & \multicolumn{6}{|c|}{ Third-floor phlebotomy unit (introduced Barricor tube) } & \multicolumn{6}{|c|}{ First-floor phlebotomy unit (did not introduce Barricor tube) } \\
\hline & Tests (N) & $\begin{array}{l}\text { Median } \\
\text { TAT (min) }\end{array}$ & $\begin{array}{c}\text { 90th } \\
\text { percentile } \\
\text { TAT (min) }\end{array}$ & $\begin{array}{l}\text { Number of } \\
\text { times } \\
\text { exceeding } \\
\text { TAT limit }\end{array}$ & $\begin{array}{l}\text { Over rate } \\
\text { (\%) }\end{array}$ & $P$ & Tests (N) & $\begin{array}{c}\text { Median } \\
\text { TAT (min) }\end{array}$ & $\begin{array}{l}\text { 90th } \\
\text { percentile } \\
\text { TAT (min) }\end{array}$ & $\begin{array}{l}\text { Number of } \\
\text { times } \\
\text { exceeding } \\
\text { TAT limit }\end{array}$ & $\begin{array}{l}\text { Over rate } \\
\text { (\%) }\end{array}$ & $P$ \\
\hline May & 4,052 & 45 & 59 & 327 & 8.07 & & 1,538 & 51 & 78 & 420 & 27.31 & \\
\hline June & 4,283 & 45 & 57 & 283 & 6.61 & & 1,562 & 52 & 77 & 448 & 28.68 & \\
\hline July & 4,148 & 45 & 59 & 346 & 8.34 & & 1,627 & 52 & 73 & 454 & 27.90 & \\
\hline August & 4,249 & 44 & 59 & 355 & 8.35 & & 1,730 & 52 & 78 & 513 & 29.65 & \\
\hline September & 4,302 & 36 & 47 & 51 & 1.19 & & 1,477 & 52 & 76 & 433 & 29.32 & \\
\hline October & 3,530 & 41 & 55 & 173 & 4.90 & & 1,326 & 55 & 77 & 460 & 34.69 & \\
\hline November & 4,154 & 38 & 50 & 95 & 2.29 & & 1,479 & 50 & 75 & 380 & 25.69 & \\
\hline December & 4,085 & 39 & 51 & 108 & 2.64 & & 1,454 & 54 & 79 & 468 & 32.19 & \\
\hline Before introduction (May-Aug) & 16,732 & 45 & 59 & 1,311 & 7.84 & & 6,457 & 52 & 76 & 1,835 & 28.42 & \\
\hline After introduction (Sep-Dec) & 16,071 & 38 & 51 & 427 & 2.66 & $<0.0001$ & 5,736 & 53 & 76 & 1,741 & 30.35 & 0.48 \\
\hline
\end{tabular}

The TAT was calculated as the time interval from the end of blood collection to the reporting of the initial results. AST was selected to monitor the TAT. Data from the first-floor phlebotomy unit, in which the Barricor tube was not introduced, for the same period are presented as a reference. $P$ was determined using the independent t-test between two periods before and after introducing the Barricor tube.

Abbreviations: TAT, turnaround time; AST, aspartate aminotransferase.

(196/924 $=21 \%)$ of the excessive TAT before the introduction of the Barricor tube. However, these reasons for excessive TAT disappeared after the introduction of the Barricor tube $(2 / 210=1 \%)$. Other reasons, such as delayed sample transport, delayed result verification, and instrument maintenance, also decreased (data not shown).

\section{Hemolysis index}

The hemolysis index decreased significantly after introducing the Barricor tube. In the two months before introducing the Barricor tube, $0.77 \%(70 / 9,104)$ of the samples requested from the third-floor phlebotomy room had a positive hemolysis index (+, ++ , or +++$)$, compared with $0.41 \%(35 / 8,459)$ in the two months after its introduction ( $P=0.0024$ by chi-square test). Because the collected samples were transported directly to the laboratory via a conveyor belt and the medical technicians in the third-floor phlebotomy unit are highly skilled, the rate of hemolysis during transport was very low. Assuming there was no change in disease severity of patients and proficiency of blood collection skills, we can conclude that the Barricor tube had a similar or smaller effect on hemolysis compared with the SST.

\section{DISCUSSION}

We introduced the Barricor tube in an outpatient phlebotomy unit located next to a laboratory in a tertiary care hospital with the aim to reduce TAT. Initially, in September 2017, we used approximately 4,000 Barricor tubes per month; currently, we use nearly 6,000 .

The Barricor tube yielded a slightly higher Tpro level and slightly lower HDL, P, and $\mathrm{K}$ levels than the SST; however, most values were within the total allowable error (TEA). Tpro level in the Barricor tube was $4.24 \%$ higher than that in SST; this could be attributed to the lack of fibrinogen in clotted serum. The $\mathrm{K}$ level in the Barricor tube was 2.69\% lower than that in the SST, consistent with the fact that serum $\mathrm{K}$ level is $0.2-0.4 \mathrm{mmol} / \mathrm{L}$ higher than that in plasma due to platelet rupture during clotting. The $\mathrm{CO}_{2}$ value was lower in the SST because $\mathrm{CO}_{2}$ was analyzed after the requested tests were completed and evaporation had occurred.

The Barricor tube has been compared with other tubes [1218]. A comparison with PST for 50 analytes in 150 patients revealed that the results for the two tubes were comparable, with increased stability for some analytes in the Barricor tube [12]. In 41 volunteers, the Barricor tube yielded decreased LDH and free hemoglobin levels compared with that in the PST [13]. Similar phenomenon of lower LDH in the Barricor tube compared with that in the SST was also observed in the recent Korean study including 30 healthy individuals [14]. In another comparative study using SST in 29 chronic hemodialysis patients, 11 had lower $\mathrm{K}$ levels in the Barricor tube; this finding was consistent with our results [15]. A comparison with the SST for 22 analytes 
in 44 blood samples showed significant increases in LDH and Tpro and a decrease in $\mathrm{K}$ in the Barricor tube [16]. Compared with the PST, 40 Barricor tube samples showed a minimal mean difference, except for a 3.2\% increase in AST [17]. Another comparative study with the PST on nine analytes in 15 patients showed acceptable differences [18]. Relative to previous studies on the Barricor tube, ours is the largest, with 166 patients. Although there were significant differences in analytes between the two tubes, they were mostly within the clinically acceptable range.

The TAT was reduced by 7 minutes in terms of the median and 8 minutes in terms of the 90th percentile after introducing the Barricor tube. While using SST, incomplete clotting led to repeated centrifugation, fibrin removal, and clogging of the analyzer aspirators. After using the Barricor tube, incomplete clotting and repeated centrifugation were reduced almost to zero. Moreover, the rate of exceeding the TAT limit decreased by onethird, and the medical technicians stated that the repeated centrifugation and analyzer needle clogging decreased after the switch. These improvements can be attributed to the additional 2-3 minutes reduction in TAT besides the 5 minutes decrease in the centrifugation time. If the clotting time had previously been followed as recommended, the reduction in TAT after the switch might have been even more noticeable. However, the real clotting time may be shorter than 30 minutes in most laboratories experiencing TAT pressures.

Some studies have investigated the effects of the Barricor tube on TAT in the phlebotomy unit and clinical laboratory $[5,6]$. In a comparison of TAT data during two six-month phases of using the SST and the Barricor tube separately, the Barricor tube significantly reduced the 90th percentile TAT from 88 to 79 minutes, especially during peak hours. The Barricor tube reduced fibrin-related remediation activities from $2.3 \%$ to $0.4 \%$, which is consistent with our results [5]. In another study regarding the switch from PST to the Barricor tube, a reduction in centrifugation time from 15 minutes to 3 minutes led to a significant reduction in TAT in an emergency department [6]. In the previous studies, TAT typically began at sample receipt, not blood collection or test request, because this stage is influenced solely by the laboratory [19]. In our study, TAT was measured from the time point at which blood collection was completed, which reflects the real-world situation; this is a strength and a unique aspect of our study.

The plastic mechanical separator in the Barricor tube may promote hemolysis. The Barricor tube has a lower hemolysis rate than other lithium heparin tubes when blood is collected via a Vacutainer, syringe, or intravenous catheter [19-21] because of the low negative pressure in the tube. Indeed, the switch to the Barricor tube resulted in a decreased hemolysis index. This lower hemolysis rate may explain the lower $\mathrm{K}$ level than that in the SST.

This study has several limitations. As we did not adhere to the recommended 30 minutes waiting time for clotting when using the SST, the reduction in TAT was smaller than the theoretical expectation. If we had adhered to the 30 minutes waiting time for clotting (including 17 minutes of waiting on average), the TAT would have been reduced by 24 minutes. The TAT and measurement ranges of samples from the intensive care unit and emergency department were not verified. These departments endeavor to decrease TAT and increase satisfaction, which is important for quality improvement [22]. Because our hospital does not accept gel-containing lithium heparin tubes for routine chemical tests, we did not perform a comparison with the PST. The Barricor tube reduces the rate of false elevation of troponin I compared with the PST and does not induce isobaric interference $[23,24]$. We introduced the Barricor tube to reduce the TAT in the outpatient phlebotomy unit for routine chemical tests; thus, further investigations of other uses of the Barricor tube are needed. A stability test was not performed, as we applied the Barricor tube for stat tests, which took approximately 45 minutes from collection to reporting.

In conclusion, the Barricor tube showed allowable differences compared with the SST. After introducing the Barricor tube, TAT was reduced owing to decreased centrifugation time and clogging-related problems. The Barricor tube might be useful in laboratories that experience frequent clogging and repeated centrifugation due to inadequate SST clotting time. Further investigation is needed on the cost-effectiveness and other unrevealed applications of the Barricor tube to reduce TAT.

\section{ACKNOWLEDGMENTS}

We thank Kinam Park of the Information Technology Department of Pusan National University Yangsan Hospital for extracting LIS data. In addition, we thank Seung Yeon Lee and the staff at BD Life Science, Korea, for providing Barricor tubes for evaluation and for technical assistance.

\section{AUTHOR CONTRIBUTIONS}

This study was designed and organized by Lee SM. Moon SY wrote the first draft and performed the statistical analysis. Lee HS and Park MS collected comparative results and turnaround 
time data. Kim IS and Lee SM provided technical support for the study as directors of the clinical laboratory and stat laboratory, respectively. All authors reviewed and approved the final manuscript.

\section{CONFLICTS OF INTEREST}

Barricor tubes were provided by BD Life Science, Korea. No further potential conflicts of interest relevant to this article are reported.

\section{RESEARCH FUNDING}

This work was supported by a clinical research grant from Pusan National University Hospital (2019).

\section{ORCID}

Soo Young Moon
Han Sol Lee
Min Soon Park
In-Suk Kim
Sun Min Lee
https://orcid.org/0000-0003-2708-5035 https://orcid.org/0000-0003-1612-8685 https://orcid.org/0000-0002-5935-6664 https://orcid.org/0000-0002-7243-9173 https://orcid.org/0000-0002-2896-3365

\section{REFERENCES}

1. Kaushik N, Khangulov VS, O'hara M, Arnaout R. Reduction in laboratory turnaround time decreases emergency room length of stay. Open Access Emerg Med 2018;10:37-45.

2. Brandhorst G, Engelmayer J, Götze S, Oellerich M, von Ahsen N. Preanalytical effects of different lithium heparin plasma separation tubes in the routine clinical chemistry laboratory. Clin Chem Lab Med 2011;49: 1473-7.

3. Ko DH, Won D, Jeong TD, Lee W, Chun S, Min WK. Comparison of red blood cell hemolysis using plasma and serum separation tubes for outpatient specimens. Ann Lab Med 2015;35:194-7.

4. Böckel-Frohnhöfer N, Hübner U, Hummel B, Geisel J. Pneumatic tubetransported blood samples in lithium heparinate gel separator tubes may be more susceptible to haemolysis than blood samples in serum tubes. Scand J Clin Lab Invest 2014;74:599-602.

5. Ramakers C, Meyer B, Yang W, Plokhoy E, Xiong Y, Church S, et al. Switching from serum to plasma: implementation of BD Vacutainer ${ }^{\circledR}$ Barricor $^{\mathrm{TM}}$ plasma blood collection tubes improves sample quality and laboratory turnaround time. Pract Lab Med 2020;18:e00149

6. Badiou S, Vuillot O, Bargnoux AS, Kuster N, Lefebvre S, Sebbane M, et al. Improved quality of samples and laboratory turnaround time using $3.5 \mathrm{~mL}$ low vacuum BD Vacutainer ${ }^{\circledR}$ Barricor tubes in the emergency department. Pract Lab Med 2019;16:e00128.

7. Guder WG and Narayanan S. Sample transport, treatment after arrival, storage and disposal. In: Guder WG, ed. Pre-examination procedures in laboratory diagnostics. 1st ed. Berlin: De Gruyter, 2015:251-64.
8. CLSI. Collection of diagnostic venous blood specimens. 7th ed. CLSI GP41. Wayne, PA: Clinical and Laboratory Standards Institute. 2017.

9. CLSI. Validation and verification of tubes for venous and capillary blood specimen collection; approved guideline. CLSI GP34-A. Wayne, PA: Clinical and Laboratory Standards Institute. 2010.

10. Aarsand AK, Fernandez-Calle P, Webster C, Coskun A, Gonzales-Lao E, Diaz-Garzon J et al. https://biologicalvariation.eu/ (Updated on 2020 May 20).

11. Ricós C, Alvarez V, Cava F, García-Lario JV, Hernández A, Jiménez CV, et al. Current databases on biological variation: pros, cons and progress. Scand J Clin Lab Invest 1999;59:491-500.

12. Fournier JE, Northrup V, Clark C, Fraser J, Howlett M, Atkinson P, et al. Evaluation of BD Vacutainer ${ }^{\circledR}$ Barricor $^{\top \mathrm{M}}$ blood collection tubes for routine chemistry testing on a Roche Cobas ${ }^{\circledR} 8000$ Platform. Clin Biochem 2018;58:94-9.

13. Cadamuro J, Mrazek C, Leichtle AB, Kipman U, Felder TK, Wiedemann $\mathrm{H}$, et al. Influence of centrifugation conditions on the results of 77 routine clinical chemistry analytes using standard vacuum blood collection tubes and the new BD-Barricor tubes. Biochem Med (Zagreb) 2018;28: 010704.

14. Shin S, Oh J, Park HD. Comparison of three blood collection tubes for 35 biochemical analytes: the Becton Dickinson Barricor tube, serum separating tube, and plasma separating tube. Ann Lab Med 2021;41: 114-9.

15. Kösem A, Topçuoğlu C, Sezer S, Cevher ŞK, Yenigün EC, Dede F, et al. Evaluation of BD Barricor ${ }^{\mathrm{TM}}$ plasma blood collection tube for biochemical tests. Clin Lab 2019;65:2315-27.

16. Arslan FD, Karakoyun I, Basok BI, Aksit MZ, Baysoy A, Ozturk YK, et al. The local clinical validation of a new lithium heparin tube with a Barrier: BD Vacutainer ${ }^{\circledR}$ Barricor LH plasma tube. Biochem Med (Zagreb) 2017; 27:030706.

17. Demeester S, Lanckmans K, Heyvaert P, Weets I, Martin M. Stability of 21 routine chemistry tests in the BD Barricor ${ }^{\mathrm{TM}}$ tube and the Sarstedt SMonovette ${ }^{\circledR}$ LH tube up to 7 days after blood collection. J Clin Chem Lab Med 2018;1:101.

18. Dupuy AM, Badiou S, Daubin D, Bargnoux AS, Magnan C, Klouche K, et al. Comparison of Barricor ${ }^{\mathrm{TM}}$ vs. lithium heparin tubes for selected routine biochemical analytes and evaluation of post centrifugation stability. Biochem Med (Zagreb) 2018;28: 020902.

19. Steindel SJ and Howanitz PJ. Physician satisfaction and emergency department laboratory test turnaround time. Arch Pathol Lab Med 2001; 125:863-71.

20. Mrazek C, Simundic AM, Wiedemann H, Krahmer F, Felder TK, Kipman $U$, et al. The relationship between vacuum and hemolysis during catheter blood collection: a retrospective analysis of six large cohorts. Clin Chem Lab Med 2017;55:1129-34.

21. Ramakers C. BD Vacutainer ${ }^{\circledR}$ Barricor tube in the emergency department: reduced hemolysis rates using partial draw tubes with reduced vacuum. Clin Chem Lab Med 2018;56:e31-2.

22. Jones BA, Walsh MK, Ruby SG. Hospital nursing satisfaction with clinical laboratory services: a College of American Pathologists Q-Probes study of 162 institutions. Arch Pathol Lab Med 2006;130:1756-61.

23. Füzéry AK, Raizman JE, Goudreau BL, Moses K, Niemann K, Park J, et al. The BD Barricor blood collection tube is an acceptable and robust alternative to the PST for use with the Beckman AccuTnl+3 assay. Clin Biochem 2017;50:851-7.

24. Mazur $\mathrm{C}$ and Hayden J. The Becton Dickinson Barricor tube does not introduce isobaric interferences in mass spectrometry-based measurements of testosterone. J Appl Lab Med 2018;2:920-4. 